\title{
Vaginal Sponge Applicator
}

National Cancer Institute

\section{Source}

National Cancer Institute. Vaginal Sponge Applicator. NCI Thesaurus. Code C150015.

Device for introducing a sponge into the vagina of an animal. 